\title{
Transformation Behaviour of Near Equiatomic TiNi Prepared by Power Metallurgy
}

\author{
Lj. Petkovski and V. Lazarov
}

Faculty of Natural Sciences and Mathematics, Institute of Physics, St. Cyril and Methodius University, Skopje, P.O. Box 162, Republic of Macedonia

\begin{abstract}
The transformation behaviour of near equiatomic TiNi alloy has been studied by a DTA method and by electrical resistance measurements between room temperature and $130{ }^{\circ} \mathrm{C}$. Series of equiatomic compound were prepared by a powder metallurgical method, viz. sintering at 850 ${ }^{\circ} \mathrm{C}$ and $900{ }^{\circ} \mathrm{C}$. The effect of thermal cycling and sintering temperature on the transformation behaviour was investigated.
\end{abstract}

\section{INTRODUCTION}

The intermetallic compound TiNi and other alloys with shape-memory effect play a most important role in obtaining progress in engineering and medicine. Historically, the identification of TiNi was first made by Vogel and Wallbaum [1]. Lawes and Wallbaum [2] were the first who wrote about the existence of the compound TiNi with a superstructure of the $\mathrm{CsCl}(\mathrm{B} 2)$ type. In the TiNi system, only the intermetallic compound TiNi shows the shape-memory effect, which means that the presence of other phases in the alloy is undesirable [3].Therefore, the object of the undertaken research was to obtain specimens containing a maximum quantity of TiNi with a nearly equiatomic composition. There are some disagreements on the equilibrium $\mathrm{Ti}-\mathrm{Ni}$ phase diagram in relation to the homogeneity region of the intermetallic compound TiNi and the temperature interval of its existence. According to Lotkov and Grishov [4] the most probable phase diagram of the Ti-Ni system, close to the equiatomic composition, nowadays, can be considered the one recommended by Wasilevski et al. [5]. It was accepted that there are three intermetallic compounds: $\mathrm{TiNi}_{\mathrm{N}} \mathrm{TiNi}_{3}$ and $\mathrm{Ti}_{2} \mathrm{Ni}$.

\section{EXPERIMENTAL}

\subsection{Specimen Preparation}

The synthesis of titanium and formation of titanium-nicked was followed by release of heat, i.e. it is an exothermic process. One of the regimes of its formation is reaction sintering. Reaction sintering can be carried out in two ways: 1) by hard phase sintering; and 2) by formation of a liquid phase as consequence of the contact melting. The realization of one of these regimes depends not only on kinetic factors (the pattern size, effective coefficient of the heat transfer and so on). Therefore the optimal conditions for making samples of a desired quality are determined by experiments. By using the method of powder metallurgy, series of nearly equiatomic Ti-Ni compounds were prepared. The starting powders for the samples produced were obtained from the firm "Merk" and had purities: Ti - 99,5\% and Ni- 99,8\%. The pressing was done by a pressure of $14,86 \mathrm{GPa}$ applied gradually during $30 \mathrm{~min}$. Two series of samples were prepared. One series was prepared by using a heating rate of $13^{\circ} \mathrm{C} / \mathrm{min}$ up to $850^{\circ} \mathrm{C}$, with a sintering time of $1 \mathrm{~h}$. Another series was prepared by using a heating rate of $5^{\circ} \mathrm{C} / \mathrm{min}$ up to $900^{\circ} \mathrm{C}$, with a sintering time of $5 \mathrm{~h}$, where the cooling rate down to room temperature was $5^{\circ} \mathrm{C} / \mathrm{min}$. The sample cooling in the first series was done in the furnace, where room temperature was reached only after $8 \mathrm{~h}$. 


\subsection{Electrical Resistance}

Measurements of the electrical resistance were carried out by the conventional direct current method described in detail in [6]. A special sample holder was constructed of bakelite, brass and brass - tip electrical contacts. Temperature variation was realized by immersing the whole assembly in a temperature controlled bath of oil. With this setup, the standard deviation in measurement of temperature was $\pm 0,1^{\circ} \mathrm{C}$.

\subsection{Differential Thermal Analysis}

In addition, a method of differential thermal analysis [6] was used for study of this compound. The register records a differential heating (and cooling) curve, viz. the sample temperature versus the temperature difference $\Delta T$ (between the sample and etalon). DTA was carried out with brass ( $60 \% \mathrm{Cu}-40 \% \mathrm{Zn})$ used as an etalon because it has similar thermal properties as the analyzed alloys, but does not have a phase transformation in the analyzed temperature range [7]. The heating and cooling rates of the furnace were determined by experiment, and were $15^{\circ} \mathrm{C} / \mathrm{min} \pm 3{ }^{\circ} \mathrm{C} / \mathrm{min}$ in both cases. Cylindrical samples with $6 \mathrm{~mm}$ diameter and $8 \mathrm{~mm}$ height were used.

\section{RESULTS AND ANALYSIS}

The electrical resistance of the samples sintered at $850^{\circ} \mathrm{C}$ and $900^{\circ} \mathrm{C}$ was measured. The dependence of resistance on temperature for the sample sintered at $850^{\circ} \mathrm{C}$ is shown in fig. 1a. for various thermal cycles. Thermal cycles were carried out from room temperature to $200{ }^{\circ} \mathrm{C}$ and vice versa. With increasing numbers of thermal cycles, the electrical resistance in the temperature region where the martensite transformation occurs, increases.

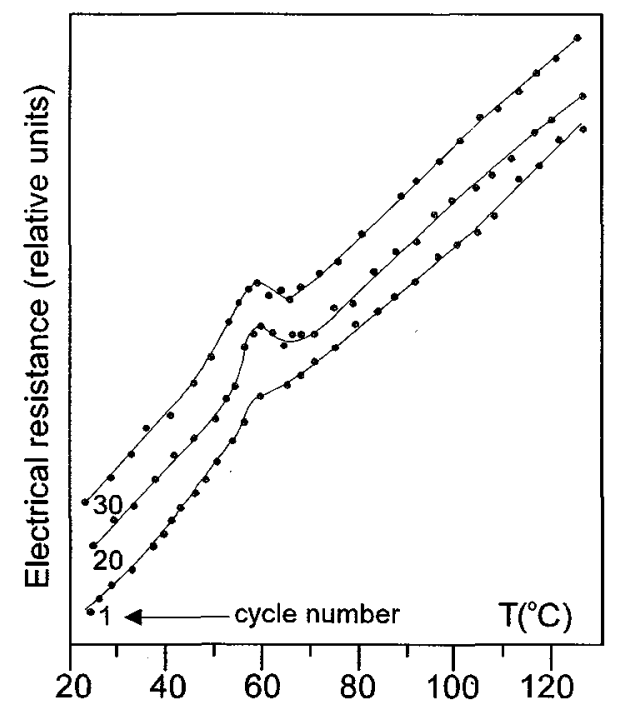

Fig. 1a. The dependence of electrical resistance on the number of thermal cycles during cooling for the samples sintered at $850^{\circ} \mathrm{C}$.

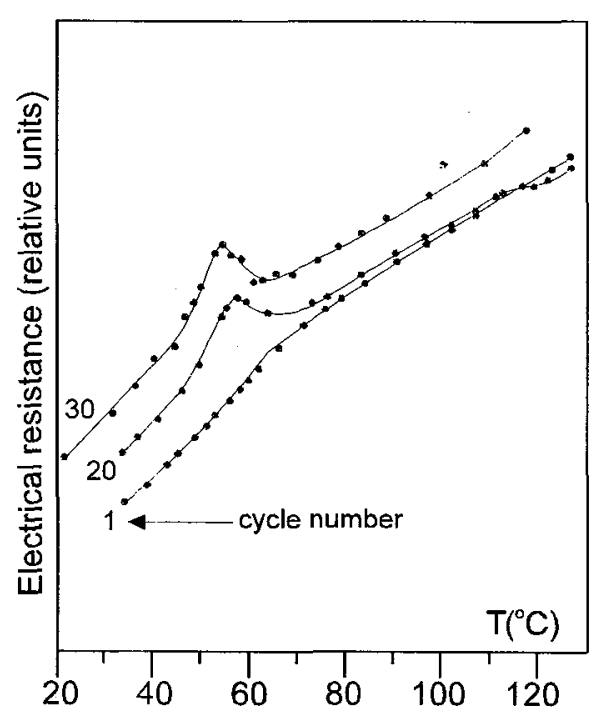

Fig. 1b. The dependence of electrical resistance on the number of thermal cycles during cooling for the samples sintered at $900^{\circ} \mathrm{C}$.

As seen from fig. $1 \mathrm{~b}$, the resistance of the sample sintered at $900^{\circ} \mathrm{C}$ (during cooling) increases much more than that of the sample sintered at $850^{\circ} \mathrm{C}$ in the temperature interval where the martensite transformation 
occurs. It is also obvious from the fig. $1 \mathrm{~b}$ that the maximum of the electric resistance shifts to lower temperatures, which is not the case with the sample sintered at $850^{\circ} \mathrm{C}$. The increase of resistance with decrease of temperature near the temperature at which the martensite transformation occurs is due to a premartensite transformation to a phase called R-phase [8].

The DTA curves have a typical form as shown in figure 2a; only one exothermic peak appears on cooling and only one endothermic peak on heating. For the martensite transformation, $M$ is taken as the peak temperature of the exothermic peak, and for the temperature of the austenite transformation, $A$ is taken as the peak temperature of the endothermic peak.

The shift in temperature of the martensite transformation due to increasing number of thermal cycles can also be seen by comparison of figures $2 a$ and $2 b$.

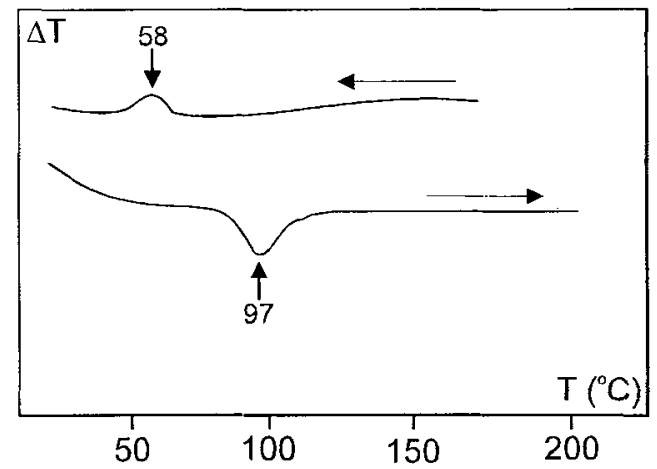

Fig. 2a. DTA cooling and heating curves for the sample sintered at $900^{\circ} \mathrm{C}$.

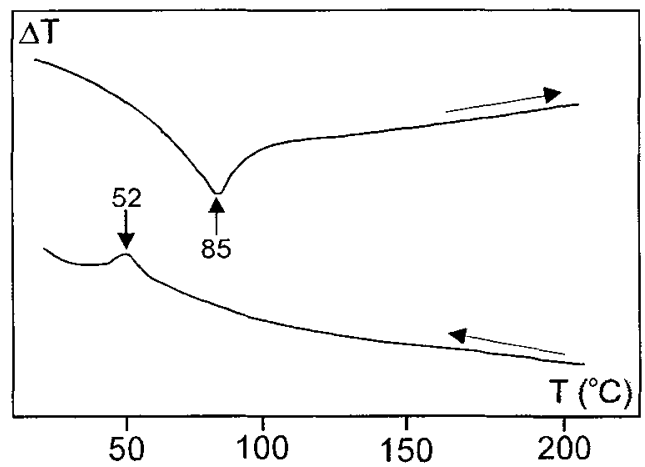

Fig. 2b. DTA cooling and heating curves for the sample sintered at $900^{\circ} \mathrm{C}$ after 30 thermal cycles.

To obtain additional information, the method of qualitative $X$ - ray phase analysis was carried out. From the recorded diffractograms, at room temperature, it was deduced that the analyzed alloys sintered at temperatures of $850^{\circ} \mathrm{C}$ and $900^{\circ} \mathrm{C}$, contain: $\mathrm{Ti}, \mathrm{Ni}, \mathrm{Ti}_{2} \mathrm{Ni}, \mathrm{TiNi}_{3}$ and $\mathrm{TiNi}$, and therefore are strongly inhomogenous.

\section{CONCLUSION}

The intermetallic compound TiNi also exists at room temperature in the samples obtained by powder metallurgy, viz. double side cold pressing, followed sintering for $1 \mathrm{~h}$ at a temperature of $850^{\circ} \mathrm{C}$ or for $5 \mathrm{~h}$ at $900{ }^{\circ} \mathrm{C}$. The thermal cycling of equiatomic TiNi decreases the temperature of the martensite transformation. This effect is larger in the case of the sample sintered at $900^{\circ} \mathrm{C}$, probably as a result of dislocations and several other structural defects. The initial temperature of the martensite transformation in the samples does not depend on the temperature of sintering. The alloy structure with the equiatomic composition of titanium and nickel, obtained by the powder metallurgical method used, is still far from the full homogeneity. There is a satisfactory correlation of the results obtained by applying different research methods. Further technological improvements for preparation of alloys by sintering also require application of additional mechanical and thermal treatments. 


\section{References}

[1] R. Vogel and H. J. Wallbaum, Arch. Eishuttenw, 12, 299 (1938).

[2] F.Lawes, H.J.Wallbaum. Natur- Wissencchaften, 27,674 (1939).

[3] I.F. Martinova, V.Ja.Petrischev, V.V.Skorohod. Poroschkovaya metatalurgiya, $N^{\circ}$ 11, 31-36 (1983).

[4] A.I. Lotkov, V.N. Grichkov Izv. Vuz. FIZIKA, 5, 68 (1985).

[5] R.J. Wasilevski, S.R. Butler, J.E. Hanlon and D. Vorden. Metallurgical Transactions, vol.2, 229-238 (1971).

[6] Lj. Petkovski, Doktorska disertacija, PMF, Skopje, 1975.

[7] M.Ristov, Lj. Petkovski, Bilten na DMF na SRM, 19, 35(1968).

[8] K. Goubaa, M. Masse and G. Bouquet, J. de Physique, 1, C4-361-366(1991). 